\title{
REPRESENTASI BUDAYA DALAM NOVEL BOENGA ROOS DARI TJIKEMBANG
}

Cultural Representation in Boenga Roos dari Tjikembang Novel

\author{
Syihaabul Hudaa ${ }^{1}$, Ahmad Bahtiar ${ }^{2}$, Novi Diah Haryanti ${ }^{3}$, Winci Firdaus ${ }^{4}$ \\ Institut Teknologi dan Bisnis Ahmad Dahlan Jakarta ${ }^{1}$ \\ UIN Syarif Hidayatullah Jakarta ${ }^{2,3}$ \\ Badan Pengembangan dan Pembinaan Bahasa ${ }^{4}$ \\ syihaabulhudaa@itb-ad.ac.id
}

\author{
Naskah diterima: 18 Januari 2021; direvisi: 11 Juni 2021 ; disetujui: 24 Juni 2021 \\ doi: https://doi.org/10.26499/jentera.v10i1.3316
}

\begin{abstract}
Abstrak
Boenga Roos dari Tjikembang bukan saja menyajikan cerita yang menarik, melainkan juga memuat unsur budaya di dalamnya. Novel ini ditulis dengan bahasa Melayu dengan mengambil latar beberapa kota di Indonesia. Salah satunya adalah Bogor, Jawa Barat. Tujuan penulisan artikel ini untuk menemukan budaya yang terdapat di dalam novel Boenga Roos dari Tjikembang karya Kwee Tek Hoay yang merupakan keturunan Tionghoa. Penelitian ini termasuk ke dalam jenis kualitatif deskriptif karena peneliti memaparkan hasil penelitiannya menggunakan teks secara deskriptif yang berfokus pada teks dan menelaah secara mendalam representasi budaya di dalam novel Boenga Roos dari Tjikembang Berdasarkan penelitian yang dilakukan, unsur kebudayaan yang ditemukan dalam novel Boenga Roos dari Tjikembang adalah kebudayaan Sunda, Jawa, dan Tionghoa.
\end{abstract}

Kata Kunci: budaya, unsur instrinsik, pendekatan objektif sastra

\begin{abstract}
Boenga Roos dari Tjikembang presents not only an exciting story but also cultural elements in it. This novel is written in Malay and takes place in several cities in Indonesia. One of them is Bogor, West Java. This article aims to find out what culturecontained in the Boenga Roos dari Tjikembang novel by Kwee Tek Hoay, a Chinese descent. This research belongs to the descriptive qualitative where the researcher describes the results of research using descriptive text focusing on text and analyzing the cultural representation of Boenga Roos dari Tjikembang in depth. Based on the research conducted, cultural elements found in Boenga Roos dari Tjikembang novel are Sundanese, Javanese, and Chinese culture.
\end{abstract}

Keywords: culture, intrinsic elements, objective approach to literature

How to Cite: Hudaa, Syihaabul, dkk. (2021). Representasi Budaya dalam Novel Boenga Roos dari Tjikembang. Jentera: Jurnal Kajian Sastra, 10(1), 45-56. Doi: https://doi.org/10.26499/jentera.v10i1.3316

\section{PENDAHULUAN}

Novel Boenga Roos dari Tjikembang meski dulu oleh seorang penulis keturunan Tionghoa adalah novel yang memuat khazanah kesusastraan Indonesia. Novel ini pertama kali diterbitkan tahun 1930. Pada saat itu, bangsa Indonesia masih menggunakan ejaan van Ophuijsen. Seperti yang sudah diketahui, ejaan yang menggunakan bahasa Melayu tersebut telah ada di Indonesia sejak abad VII pertengahan era kerajaan Sriwijaya (Bahtiar et al., 2019). 
Kemudian, ejaan yang menggunakan bahasa Melayu tersebut dibukukan oleh van Ophuijsen tahun 1901 dalam Kitab Logat Melayu. Ejaan van Ophuijsen tersebut digunakan di Indonesia cukup lama hingga kemudian digantikan oleh ejaan yang dikenal dengan nama Ejaan Soewandi (1947) (Bahtiar et al., 2019).

Penggunaan bahasa yang masih menggunakan ejaan van Ophuisjen membuat novel ini tidak relevan dengan generasi milenial yang tidak terbiasa membaca Ejaan Melayu (Ningsih, Rasyid, \& Muliastuti, 2018). Terlebih, adanya gabungan dua huruf yang dibaca menjadi satu huruf dan menjadi huruf yang berbeda /tj/ dibaca /c/ yang membuat novel ini menjadi tidak mudah dan mengurangi kenikmatan pembaca yang tidak terbiasa dengan ejaan tersebut.

Di samping itu, Seiring masuknya teknologi dan zaman yang terus berubah, novel karya penulis Indonesia semakin dilupakan. Misalnya saja saat era modern seperti saat ini, posisi novel sudah tergantikan oleh Netflix, Iflix, Viu, dan situs lainnya yang menyajikan film Korea (Lee \& Yoo, 2011). Padahal, novel berbahasa Melayu menyajikan karya yang berbeda dan memiliki daya tarik tersendiri. Selain karena keunikan bahasa Melayu yang digunakan pada zaman itu, juga karena novel tidak lahir dari kekosongan budaya dan pengarang mengekspresikan budaya tersebut melalui karyanya

Demikian halnya dengan novel Boenga Roos dari Tjikembang. Novel tersebut tidak hanya menyajikan romantisme tokoh di dalamnya, melainkan ada nilai lain, seperti: budaya, religiositas, dan sosial. Kendati demikian, novel ini justru dikenal oleh khalayak umum dengan kisah romantis antara Aij Tjeng, Gwat Nio, dan Marsiti. Cinta yang tulus dan sederhana akan tetap menyatu, walaupun telah berbeda alam, tetapi cinta itu tetap abadi. Romantisme inilah yang kerap diidolakan sebagai suatu bentuk cinta dunia-akhirat bagi pemuda-pemudi pada masa itu (Hogarth, 2013). Namun, di sisi lain, novel Boenga Roos dari Tjikembang ini menarik dikaji. Dari segi percetakan, novel ini yang paling banyak dicetak ulang dibanding novel-novel semasanya yang menunjukkan antusiasme pembacanya. Selain itu, novel ini juga telah mengalami berbagai transformasi, dari cerita bersambung menjadi drama panggung, film, dan buku. Kendati menggunakan ejaan van Ophuisjen, dalam novel tersebut ditemukan penggunaan berbagai bahasa seperti Belanda, Sunda, dan Inggris. Oleh karena itu, penelitian ini bertujuan mengkaji representasi budaya yang terkandung di dalam novel Boenga Roos dari Tjikembang.

Penelitian yang membahas tentang representasi budaya di dalam novel pernah dilakukan oleh beberapa peneliti. Di antaranya, Hidayah dkk., tahun 2016 yang membahas tentang budaya Jawa dan Barat serta akulturasi budaya Jawa dan Barat dalam novel Rahvayana karya Sujiwo Tejo (Hidayah;, Hermoyo, \& Yarno;, 2016). Hasil penelitian ini menemukan 
representasi budaya Jawa dalam novel Rahvayana karya Sujiwo Tejo menampilkan berbagai sikap, adat, ritual sebagai suatu budaya masyarakat Jawa. Misalnya saja seperti upacara kematian, panggih, dan tedak Siti.

Representasi budaya barat yang terdapat dalam novel ini meliputi sikap individualistik yang tercermin dalam budaya barat, seperti gaya hidup bebas,cara berpikir, dan bertindak yang mengutamakan sikap disiplin. Sebaliknya, akulturasi budaya Jawa dan Barat yang ditemukan di dalam novel ini, di antaranya terjadinya seks bebas, gaya hidup, dan tafsir mimpi yang berkembang di Jawa dan Barat. Tentu saja kedua budaya tersebut menjadi suatu hal yang berbeda dan menarik untuk dikaji (Sugiyanto, 2021).

Penelitian lainnya tentang representasi budaya dalam novel dilakukan oleh Maspuroh tahun 2015 dengan judul "Kajian Bandingan Struktur dan Nilai Budaya Novel Amba dan Novel Perjalanan Sunyi Bisma Dewabrata (Maspuroh, 2015)." Penelitiannya menemukan novel Amba merupakan bentuk restorasi, yaitu sebagai ungkapan dari keinginan, kerinduan, dan nostalgia yang mengingatkan kembali kepada kekuatan wayang pada zaman modern.

Novel Perjalanan Sunyi Bisma Dewabrata merupakan bentuk afirmasi, yang menetapkan norma sosio-budaya yang ada pada waktu tertentu dan merupakan bentuk pengukuhan dari cerita pewayangan yang ideal pada masa tertentu. Perbandingan nilai budaya didapatkan melalui representasi nilai-nilai budaya dalam novel Amba dan novel Perjalanan Sunyi Bisma Dewabrata yang merujuk pada lima masalah dasar dalam hidup sesuai dengan nilai budaya yang telah dikemukakan Kluckhohn.

Dari beberapa penelitian yang sudah dilakukan oleh peneliti sebelumnya terkait dengan representasi nilai budaya dalam novel, penelitian ini memiliki perbedaan. Penelitian ini dilakukan untuk menemukan representasi budaya yang dimunculkan dalam novel melalui teks yang ada di dalamnya, baik itu melalui teks secara langsung, maupun secara semiotika. Dari temuan tersebut, peneliti mengidentifikasi representasi budaya yang ada di dalam novel Boenga Roos dari Tjikembang.

\section{LANDASAN TEORI}

\section{Representasi Budaya}

Representasi merupakan produksi makna melalui bahasa (Hall \& Open University., 1997). Novel ini menampilkan konsep budaya yang unik dan menarik karena pertemuan berbagai budaya tersaji di dalamnya. Ragam budaya ini membuat terjadinya interaksi yang melibatkan budaya berbeda (Ridwan, 2016). Misalnya saja interaksi antarbudaya yang terjadi 
di kota besar seperti Jakarta, antara suku Jawa, Sunda, Medan, dan suku lainnya. Dari komunikasi yang dilakukan secara intensif, muncul kerja sama yang saling menguntungkan satu sama lain. Samovar et al. (2000) mengatakan bahwa komunikasi antarbudaya terjadi ketika anggota dari satu budaya tertentu memberikan pesan kepada anggota dari budaya yang lain. Artinya, antara pengirim pesan dan penerima pesan berbeda latar belakang budayanya.

Komunikasi antarbudaya menjadi simbol keberagaman masyarakat multikultural yang perlu dilestarikan (Barker, 2003). Salah satu contoh bentuk interaksi antarbudaya yang terjadi di Indonesia dan terdiri atas masyarakat multikultural yaitu Pulau Jawa. Pulau Jawa menjadi tujuan masyarakat dari berbagai pulau di Indonesia untuk mencari penghidupan yang lebih baik. Di Pulau Jawa, pelbagai suku yang memiliki karakteristik yang berbeda bertemu dan berbaur satu sama lain. Adapun kebudayaan menurut Koentjaraningrat (2004) secara universal memiliki tujuh unsur, yaitu: (1) sistem religi dan upacara keagamaan; (2) sistem dan organisasi kemasyarakatan; (3) sistem pengetahuan; (4) bahasa; (5) kesenian; (6) sistem mata pencaharian hidup; dan (7) sistem teknologi dan peralatan.

Tujuh konsep kebudayaan secara universal ini digunakan untuk menganalisis temuan data dalam penelitian. Dengan menggunakan konsep kebudayaan secara universal ini, data akan diklasifikasikan dan diuraian secara mendalam.

\section{METODE PENELITIAN}

Metode penelitian yang dilakukan di dalam penelitian ini termasuk ke dalam jenis kualitatif deskriptif. Dalam penelitian kualitatif deskriptif peneliti menjelaskan hasil temuan penelitian menggunakan teks secara deskriptif (Sugiyono, 2016). Temuan penelitian dibahas secara detail menggunakan pendekatan studi analisis isi (Moleong, 2017). Pendekatan analisis isi dipilih agar peneliti fokus pada teks yang ada di dalam suatu bahan kajian (Emzir, 2017). Dengan melakukan kajian analisis isi, peneliti dapat fokus pada teks dan menelaah secara mendalam representasi budaya di dalam novel Boenga Roos dari Tjikembang.

\section{PEMBAHASAN}

\section{Boenga Roos dari Tjikembang}

Boenga Roos dari Tjikembang (Bunga Roos dari Cikembang) merupakan novel karya Kwee Teek Hoay (1927) yang menggunakan bahasa Melayu Rendah. Novel ini menceritakan kisah tentang seorang manager perkebunan Aij Tjeng yang harus meninggalkan nyai (Marsiti). Dari hasil hubungannya, mereka memiliki anak yang bernama Roosminah. Akan tetapi, Aij 
Tjeng tidak mengetahui Marsiti sedang hamil saat berpisah dengannya. Roosminah memiliki kemiripan wajah dengan Lily (anak Aij Tjeng) yang meninggal. Akhirnya, Bian Koen menikah dengan Roosminah yang memiliki wajah mirip dengan Lily. Takdir seakan mempersatukan kembali cinta dan kasih layaknya cinta Aij Tjeng dan dan Marsiti di masa lampau.

Kisah cinta Aij Tjeng dan Marsiti yang kandas karena dijodohkan dengan Gwat Nio, membuat perasaannya sempat tidak karuan. Walaupun Marsiti hanya seorang selir, tetapi Aij Tjeng menyayangi Marsiti tulus dari dalam hatinya. Perpisahan Aij Tjeng dan Marsiti rupanya bukanlah perpisahan untuk terakhir kalinya. Hal ini dikarenakan mereka akan berjumpa kembali dengan kisah cinta yang dilanjutkan oleh keturunan mereka.

\section{Representasi Budaya Sunda-Jawa}

Seperti yang sudah dibahas sebelumnya, di dalam novel terdapat unsur penunjang secara intrinsik dan ekstrinsik. Novel bukan saja menyajikan cerita yang menarik untuk dibaca, melainkan ada pesan yang tersirat dan tersurat yang berfungsi sebagai nasihat. Dalam kajian ini, peneliti memfokuskan pada representasi budaya yang terdapat di dalam novel ini dan mengidentifikasinya. Berikut temuan hasil penelitian yang dilakukan oleh peneliti.

Dalam novel Boenga Roos dari Tjikembang, representasi budaya Sunda muncul melalui teks yang digunakan tokoh dalam berkomunikasi. Berikut temuan hasil penelitian yang pertama.

"Tapi maski begitu paman-paman tani musti bekerja giat, aken pacul itu di tanah-tanah yang lembek lantaran ujan...." (Hoay, 1927: 301).

Kalimat di atas menunjukkan adanya latar belakang tanah Priangan (Jawa Barat). Indonesia adalah negara agraris sehingga bertani merupakan salah satu profesi yang ditekuni oleh masyarakatnya. Petani dikenal memiliki jiwa yang pantang menyerah dan sikap giat dalam bekerja. Setiap pagi, masyarakat yang berprofesi sebagai petani sudah bangun pagi dan menyiapkan alat yang digunakan untuk berangkat ke sawah. Dalam novel, citra petani direpresentasikan dalam teks ini sebagai seseorang yang giat dalam bekerja demi memenuhi kebutuhan keluarganya. Masyarakat yang tergolong suku Jawa dan Sunda, dikenal memiliki pribadi yang gigih dalam bekerja. Kegigihan tersebut membudaya dalam masyarakat.

Temuan berikutnya berkaitan dengan budaya masyarakat Sunda dalam kaitannya dengan konsep dan sistem organisasi kemasyarakatan. Konsep organisasi kemasyarakatan dalam budaya Sunda berkaitan dengan perilaku atau kebiasaan yang dilakukan oleh masyarakat. 
“... prampuan yang lagi masak nasi, yang tercampur juga dengan wanginya ikan asin yang digoreng atawa dibakar, hingga menjadi penyambutan yang sanget memuasken hati pada itu kuli-kuli yang pulang karumahnya sasudahnya bekerja keras dan cape antero hari." (Hoay, 1927: 301).

Menurut Koentjaraningrat, sistem dan organisasi kemasyarakatan merupakan suatu hal yang mengatur tentang perilaku masyarakat dalam kesehariannya (Koentjaraningrat, 1984). Memasak nasi liwet merupakan tradisi masyarakat Sunda yang biasa dilakukan ketika berkumpul bersama keluarga, rekan sejawat, atau pun kunjungan lainnya dalam jumlah besar. Sampai saat ini, tradisi ngeliwet, memasak ikan asin dengan cara dibakar, masih dilakukan oleh masyarakat Sunda saat menyambut keluarga mereka yang berkumpul. Selain itu, ngeliwet pun mulai dilakukan oleh sebagian masyarakat Jawa yang dipengaruhi oleh budaya Sunda. Cita rasa kebersamaan yang muncul saat menikmati makan bersama, membuat rasa makanan yang dimakan semakin nikmat.

$$
\text { “...roko kaung...." (Hoay, 1927: 302). }
$$

Rokok kawung merupakan salah satu budaya masyarakat yang saat ini dikenal dengan istilah ngelinting. Tembakau yang digunakan merupakan hasil panen dari perkebunan pribadi atau membeli dari petani. Rokok kawung biasanya dibungkus menggunakan daun aren yang dicampur dengan cengkih. Saat dibakar, wangi khas dan bunyi "kretek-kretek" akan muncul ketika terkena api. Tradisi mengisap rokok ini dilakukan oleh masyarakat Jawa danSunda pada masa kolonial Belanda. Mereka yang mengisap rokok ini, tentunya bukan dari golongan masyarakat miskin. Karena rokok zaman dahulu hanya diperuntukkan untuk priyayi.

\footnotetext{
"la berdiri di samping satu meja knap, tangan yang satu pegang tasch kecil, yang sablah lagi memegang payung. Bajunya cita tablo, dan lehernya dilibet satu halsduk." (Hoay, 1927: 336).
}

Gaya berpakaian wanita yang menjadi tren saat itu digambarkan melalui kutipan di atas. pakaian tersebut biasanya digunakan saat mengikuti acara tertentu atau kegiatan berfoto. Halsduk (syal) menjadi hiasan wajib di leher. Gaya berpakaian wanita yang digambarkan pada novel tersebut adalah gaya berpakaian tahun 1927. Perempuan pribumi atau pun pendatang menggunakan gaya berpakaian ini. Gaya berpakaian menurut Koentjaraningrat (1985) termasuk ke dalam kesenian yang diwariskan secara turun temurun mengikuti perkembangan budaya. Seni berpakaian bagi masyarakat merupakan identitas dan pembeda antara masyarakat lokal dengan masyarakat pendatang. Zaman dahulu, kaum pribumi dan masyarakat pendatang dapat dilihat perbedaannya dengan jelas melalui busana yang digunakan.

“...topi kebon, kakinya dilibet puttess, dengan pake kemeja sacara cowboy...." (Hoay, 1927: 336). 
Gaya berpakaian pria pribumi (kaya), Tionghoa, atau kalangan terpelajar disebutkan dalam kutipan di atas. Gaya berpakaian ini tren tahun 1920-an dan digunakan dalam acara formal atau kegiatan tertentu. Masyarakat yang menggunakan gaya berpakaian model ini, biasanya memiliki pengetahuan yang lebih daripada masyarakat lainnya. Identitas budaya yang muncul dari gaya berpakaian model ini adalah kalangan terpelajar, priyayi, dan tuan tanah yang dianggap memiliki derajat lebih tinggi.

“Apakah kau tida coba suru sinhe khoamia liatin ia punya peji." (Hoay, 1927: 346).

Khoamia didefinisikan sebagai ramalan. Kalimat ini menunjukkan adanya kepercayaan terhadap ramalan yang merupakan kebudayaan Tionghoa. Masyarakat Tionghoa percaya dengan ramalan dan shio. Bahkan, di antara mereka ada yang sepenuhnya menggantungkan harapan dari ramalan yang didapatkan. Dalam teori kebudayaan menurut Koentjaraningrat, sistem religi dan upacara keagamaan masih menjadi kepercayaan yang dianut masyarakat Indonesia (Koentjaraningrat, 1985b). Kendati ramalan, shio, dan zodiak yang secara teori belum dapat dipercayai kebenarannya, tetapi sebagian orang memercayainya. Budaya memercayai ramalan dan hal gaib ini diwariskan turun temurun di Indonesia. Misalnya saja malam satu suro yang dianggap malam sakral oleh mereka yang memiliki peliharaan gaib.

“Juragan teh ngaronda? Linggih atuh." (Hoay, 1927: 363).

Ronda masih menjadi budaya yang dilakukan masyarakat Indonesia, bahkan sampai era modern. Dalam teori kebudayaan, ronda termasuk ke dalam sistem dan organisasi kemasyarakatan yang ada di masyarakat. Ronda didefinisikan sebagai suatu kegiatan di malam hari yang bertujuan menjaga kampung sekitar. Zaman dahulu, ronda dilakukan untuk mencegah perampok di kampung masuk yang biasanya mencuri rumah warga atau hewan ternak. Bahkan, di beberapa tempat, ronda memiliki mitologi tersendiri, yaitu menjaga perempuan yang sedang hamil tua atau hendak melahirkan. Mitosnya, saat perempuan sedang hamil tua atau dalam masa penantian persalinan makhluk gaib berada di sekitarnya.

“...bikin tumpeng dari nasi begana, rujak-rujakan sedia kembang tuju rupa, telor ayam dan laenlaen keperluan."(Hoay, 1927: 369).

Nasi tumpeng dalam budaya masyarakat Indonesia biasanya dibuat menyambut upacara tertentu. Tradisi tumpengan dalam perspektif sistem religi dan upacara keagamaan merupakan suatu hal yang tidak dapat dipisahkan. Sampai saat ini, tradisi tumpengan masih dilakukan dalam kebudayaan Jawa dan Sunda. Tradisi Nyadren, dalam kebudayaan Jawa misalnya selalu 
menyajikan tumpengan dengan menu pelengkap seperti ayam, telur, dan makanan lainnya. Jika dalam suatu kegiatan seperti nyadren atau peringatan upacara tertentu tidak ada nasi tumpeng, ada anggapan yang berkembang mengenai kurangnya keberkahan yang akan diterima oleh pemilik acara.

"Rumahnya ada dari bilik model panggung seperti biasanya kebanyakan rumah-rumah di Priangan buat di desa itu rumah ada sampe besar dan indah dicat biru langit dan beratep genteng." (Hoay, 1927: 372).
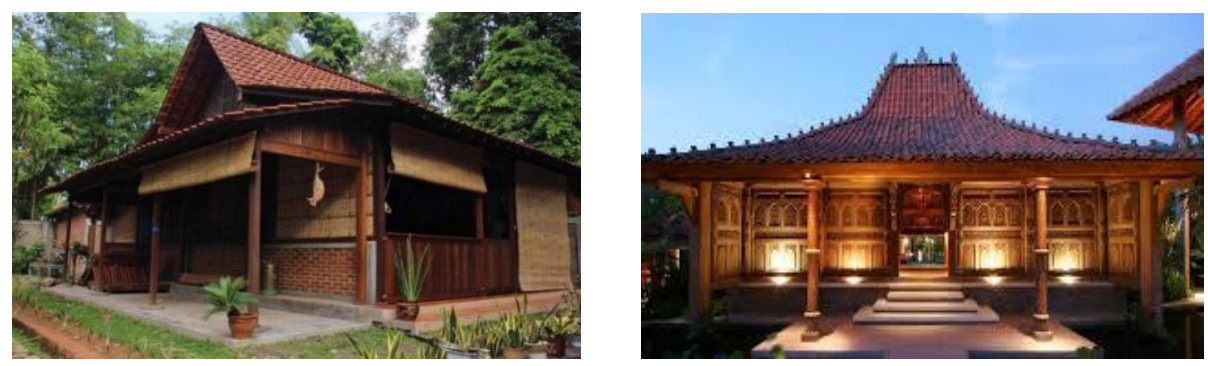

Gambar 1. Imah Jolopong dan Joglo

Rumah bilik dengan model panggung dikenal dengan istilah Imah Jolopong (Sunda) dan Joglo (Jawa). Kedua rumah ini merupakan rumah adat khas daerahnya masing-masing. Sisinya terbuat dari bilik, bagian atasnya menggunakan genting yang terbuat dari tanah liat. Rumah adat termasuk ke dalam kesenian yang dimiliki oleh masyarakat yang dipengaruhi oleh budaya turun temurun. Struktur bangunannya dibuat seragam mengikuti kebiasaan yang ada sehingga terlihat kekompakan dalam membangun suatu desa. Tradisi membangun rumah di daerah yang dahulu menjadi ciri khas suatu daerah, kini berkembang di wilayah perkotaan. Rumah adat tertentu memberikan citra yang berbeda untuk pemiliknya. Selain itu, keunikan ini memberikan konsep seni yang tinggi di lingkungan masyarakat multikultural.

"Di samping rumah ada mengalir satu solokan aer sawah yang jato ka satu empangan...." (Hoay, 1927: 372).

Memelihara ikan bagi masyarakat Sunda yang tinggal di dekat sumber air merupakancara terbaik mengoptimalkan hunian. Ikan menjadi lebih sehat di air yang mengalir dan mudah dalam mendapatkan makanan. Dalam unsur universal budaya, memelihara ikan merupakan sistem teknologi dan peralatan. Masyarakat membuat jalur air yang mengalir dari pegunungan, kemudian ditambahkan pipa yang masuk ke dalam rumah masyarakat. Dengan adanya air dari gunung, mereka tidak perlu khawatir kekurangan air bersih.

"Di sablah blakang ada kaliatan satu lumbung padi dan dua kendang buat kambing dan domba." (Hoay, 1927: 373). 
Memiliki lumbung padi dan kandang kambing/domba yang terletak di sebelah atau di sekitar rumah merupakan tradisi budaya masyarakat Jawa. Di Jawa khususnya Jawa Tengah, Jawa Timur, beternak dan menyimpan hasil panen berupa padi di samping rumah sudah menjadi budaya yang diturunkan secara turun-temurun. Dalam tradisi masyarakat Jawa, memelihara hewan ternak di depan rumah dianggap kurang baik. Oleh karena itu, kebanyakan dari masyarakat yang memiliki hewan ternak biasanya memelihara hewan ternak mereka di sebelah rumah atau pun di belakang rumah.

“...silahken itu 'Juragan Tanah' dan 'Juragan Istri' naek di atas tepas dan duduki di korsi, sedeng si tuan rumah bersila di atas tiker." (Hoay, 1927: 373.

Dalam budaya masyarakat Jawa/Sunda dikenal adanya perbedaan status sosial.Kutipan di atas menunjukkan bahwa pemilik rumah sudah biasa menyediakan tempat yang lebih tinggi kepada orang yang dianggap memiliki derajat lebih tinggi. Walaupun orang tersebut merupakan tamu, tetapi memiliki derajat yang dianggap lebih tinggi, pemilik rumah akan duduk di bawah sambil bersila. Sampai saat ini, budaya seperti ini masih terjadi di masyarakat. Misalnya saja ketika ada kunjungan dari orang yang dianggap penting, seperti: tokoh masyarakat, ulama, atau pun pemiliki tanah, maka tuan rumah yang dikunjungi akan menyilakan tamunya duduk di atas. Sebaliknya, pemilik rumah akan duduk di bawah sambil menatap ke bawah sebagai bentuk tingkatan yang berbeda.

“...Rosminah sekarang ada berdandan rapih, pake baju batik puti dengan kembang borduur puti sabagi yang banyak dipake para prampuan Tionghoa, dengen sarung "Tiga Nagri"...." (Hoay, 1927: 374).

Gaya berpakaian Roos merupakan budaya masyarakat Tionghoa yang ada di Indonesia tahun 1900-an. Selain digunakan perempuan Tionghoa, gaya berpakaian menggunakan batik dengan kembang, di bawahnya menggunakan sarung juga banyak dipakai perempuan asing (Eropa) yang ada di Indonesia. Sarung Tiga Nagri merupakan sarung batik khas Jawa yang dibuat dengan motif bunga. Gaya berpakaian ini termasuk ke dalam unsur seni di dalam suatu kebudayaan. Penggunaan gaya berpakaian menunjukkan identitas penggunanya yang dapat dikatakan kaum terpandang atau kaum biasa. Selain menunjukkan identitas, gaya berpakaian dalam era modern menjadi citra budaya suatu bangsa.

"Kenapa begitu? la toch sudah cukup umur aken menika. Bukan satu adat kabiasaan dari orang desa aken sekep gadisnya sampai begini besar?" (Hoay, 1927: 374.

Salah satu budaya Sunda yang tersirat di dalam kutipan di atas adalah mengawinkan 
anak perempuan meski masih berusia dini apabila sudah ada yang tertarik meminangnya. Anak perempuan yang sudah masuk usia gadis tabu dibiarkan tinggal di dalam rumah dan disembunyikan dari masyarakat. Kepercayaan masyarakat Sunda menganggap bahwa anak gadis mereka jika sudah ada yang ingin meminang, maka segera dinikahkan. Biasanya, anakanak usia 14-18 tahun sudah dianggap pantas untuk menikah sehingga mereka tidak akan tinggal bersama orang tuanya lagi. Pandangan ini muncul berdasarkan asas kepercayaan yang dianut di masyarakat. Mereka yang menikah dan memiliki anak akan bertambah berkah hidupnya. Selain itu, adanya anak di usia muda membuat mereka terbantu pekerjaannya kelak saat tua tiba.

"Hamba sesalin kenapa ia pergi ka kburun ibunya sendirian zonder ada perlu apa-apa." (Hoay, 1927: 377).

Ziarah makam menjadi tradisi masyarakat Indonesia. Tradisi ziarah kubur masih ada sampai saat ini, baik dalam masyarakat sukuJawa (nyekar) maupun Sunda (nyekar, kuningan). Sistem religi dan upacara keagamaan dalam unsur kebudayaan membuat suatu tradisi yang diwariskan turun-temurun dan tidak dapat dihilangkan. Salah satunya adalah nyekar yang biasa dilakukan menjelang Ramadan tiba. Biasanya, masyarakat yang mengunjungi makam membacakan doa dan menaburkan kembang serta air melati. Akan tetapi, perkembangan zaman mengubah persepsi masyarakat. Sebagian masyarakat modern tidak lagi melakukan tradisi ini karena mereka menganggap cukup mengirimkan doa kepada arwah yang telah tiada.

"Suara muziek dan gamelan yang dibunyiken aken sambut tetamu-tetamu...." (Hoay, 1927: 408).

Musik gamelan merupakan tradisi budaya masyarakat Jawa dan Sunda. Penggunaan alat musik ini biasanya digunakan dalam acara tertentu seperti: pernikahan, pewayangan, dan pementasan tertentu. Sebagai suatu bentuk kesenian, musik dan gamelan menjadi pengiring tamu. Biasanya penggunaan musik ini dalam era saat ini tidak mengenal acara tertentu. Bahkan, penggunaan musik ini sering kali dipertunjukkan kepada pemelajar asing (BIPA) yang sedang mempelajari budaya Indonesia.

Secara keseluruhan hasil temuan penelitian yang sudah dibahas oleh peneliti disajikan secara konkret melalui diagram di bawah ini: 


\section{Representasi Budaya}

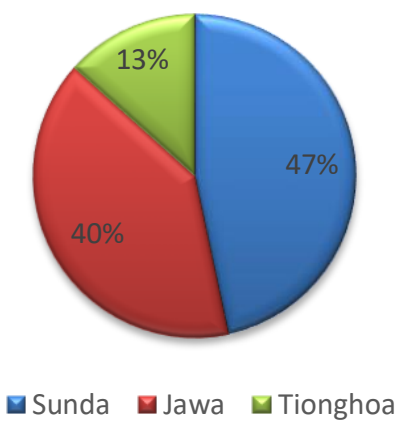

Gambar 2. Representasi Temuan Budaya

Dari pembahasan yang diuraikan di atas, ditemukan bahwa dalam novel Boenga Roos dari Tjikembang terdapat nilai budaya Sunda, Jawa, dan Tionghoa di dalamnya. Budaya Sunda dalam novel ini ditemukan sebanyak 14 kutipan yang diperoleh dari dialog di dalam novel. Kemudian, budaya Jawa sebanyak 12 kutipan yang diperoleh dari dialog di dalam novel, dan 4 representasi budaya Tionghoa. Angka tersebut kemudian disajikan dalam bentuk diagram berupa persentase budaya Sunda sebesar 47\%, Jawa sebesar 40\%, Tionghoa 13\% yang di dalamnya terdapat konsep sistem religi dan upacara keagamaan, sistem dan organisasi kemasyarakatan, kesenian, sistem mata pencaharian hidup, dan sistem teknologi dan peralatan. Dengan demikian, Kwee Tek Hoay yang merupakan pengarang berlatar belakang Tionghoa tidak meninggalkan jati dirinya dan tidak juga mengabaikan budaya tempat tinggalnya. Representasi budaya disampaikan penulis dengan detail melalui teks yang terdapat di dalamnya secara eksplisitsehingga pembaca dapat memahami pesan budaya yang disampaikan.

\section{SIMPULAN}

Berdasarkan penelitian yang dilakukan, dalam novel Boenga Roos dari Tjikembang ditemukan nilai budaya Sunda, Jawa, dan Tionghoa. Penulisnya yang memiliki latar belakang Tionghoa memadukan unsur budaya secara ekspresif melalui novel ini. Kultur budaya tempat penulis tinggal memengaruhi imajinasi penulis dalam menuliskan karyanya. Tokoh-tokoh yang ada di dalamnya pun merepresentasikan nilai kearifan lokal masyarakat Jawa, Sunda, dan Tionghoa (berasal dari penulis). Perpaduan ini membuat novel kaya akan kebudayaan Jawa, Sunda, tetapi tidak menghilangkan identitas penulisnya yang memiliki darah Tionghoa.

Sebagai suatu bahan bacaan sastra, novel Boenga Roos dari Tjikembang memiliki nilai budaya yang diimplementasikan melalui teks di dalamnya. Pembaca dapat menemukan ada $40 \%$ budaya Jawa, $47 \%$ budaya Sunda, dan $13 \%$ budaya Tionghoa. 


\section{DAFTAR PUSTAKA}

Bahtiar, A., Erowati, R., \& Haryanti, N. D. (2019). Revolusi dalam Dua Novel Indonesia: Sebuah Bandingan. Buletin Al-Turas. https://doi.org/10.15408/bat.v25i2.10228

Bahtiar, A., Nuryani, \& Hudaa, S. (2019). Khazanah Bahasa: Memaknai Bahasa Indonesia dengan Baik dan Benar (1st ed.). Bogor: In Media. Retrieved from http://penerbitinmedia.co.id/search/?q=khazanah bahasa

Barker, C. (2003). Agency and the politics of identity. Cultural Studies: Theory and Practice(2nd Edition), pp. 233-245.

Emzir. (2017). Metodologi penelitian pendidikan kuantitatif \& kualitatif. In Metodologi penelitian pendidikan kuantitatif \& kualitatif.

Hall, S., \& Open University. (1997). Representation : cultural representations and signifying practices. Sage in association with the Open University.

Hidayah;, N., Hermoyo, R. P., \& Yarno; (2016). Representasi budaya jawa dan barat dalam novel rahvayana karya sujiwo tejo. Jurnal STILISTIKA.

Hoay, K. T. (1927). Boenga Roos dari Tjikembang. Hindia-Belanda: Panorama.

Hogarth, H. K. K. (2013). The Korean wave: An Asian reaction to western-dominated globalization. Perspectives on Global Development and Technology. https://doi.org/10.1163/15691497-12341247

Koentjaraningrat. (1984). Kebudayaan Jawa. Balai Pustaka.

Koentjaraningrat. (1985a). Javanese culture. Oxford University Press.

Koentjaraningrat, K. (1985b). Mentalitas dan Pembangunan. Jakarta: Gramedia.

Koentjaraningrat, K. (2004). Kebudayaan, mentalitas dan pembangunan. repository.umpalembang.ac.id. Retrieved from http://repository.um-palembang.ac.id/id/eprint/8986

Lee, T. H., \& Yoo, J. K. (2011). A study on flow experience structures: Enhancement or death, prospects for the korean wave. Journal of Travel and Tourism Marketing. https://doi.org/10.1080/10548408.2011.571578

Maspuroh, U. (2015). KAJIAN BANDINGAN STRUKTUR DAN NILAI BUDAYA NOVEL AMBA DAN NOVEL PERJALANAN SUNYI BISMA DEWABRATA. Riksa Bahasa: Urnal Bahasa, Sastra, Dan Pembelajarannya.

Moleong, L. J. (2017). Metodologi Penelitian Kualitatif (Edisi Revisi). In PT. Remaja Rosda Karya.

Ningsih, S. A., Rasyid, Y., \& Muliastuti, L. (2018). Analisis Kebutuhan Materi Ajar Membaca BIPA A1 dengan Pendekatan Deduktif di SD D'Royal Moroco. PEMBELAJAR: Jurnal Ilmu Pendidikan, Keguruan, Dan Pembelajaran. https://doi.org/10.26858/pembelajar.v2i2.5974

Ridwan, A. (2016). Komunikasi Antarbudaya Mengubah Persepsi dan Sikap dalam Meningkatkan Kreatifitas Manusia. Bandung: CV Pustaka Setia.

Samovar, Larry, Porter, R. E., \& Stefani, L. A. (2000). Communication Between Cultures. New York: Wadsworth Publishing Company.

Sugiyanto, B. A. W. (2021). Hibriditas Budaya Jawa dan Budaya Barat di Museum Keraton Yogyakarta. Jurnal Ilmiah Multimedia Dan Komunikasi. Retrieved from http://ojs.mmtc.ac.id/index.php/jimk/article/view/107

Sugiyono. (2016). Memahami Penelitian Kualitatif. Bandung: Alfabeta.

Timomor, Rachmi. (2020). 11 Contoh Rumah Adat di Indonesia dengan Desain Unik. [https://www.99.co/id/panduan/contoh-rumah-adat]. 99.co. 